Resenha

\title{
Saúde mental no trabalho: da teoria à prática
}

GLINA, Débora Miriam Raab; ROCHA, Lys Esther. (Org.). São Paulo: Roca, 2010. 444p. ISBN: 978-85-7241-862-1

Glina e Rocha, que já haviam organizado livro (GLINA; ROCHA, 2000) sobre o tema em 2000, presenteiam-nos com a chegada ao público da obra Saúde Mental no trabalho: da teoria à prática.

Trata-se de publicação essencial, que visa a instrumentalizar os profissionais da Saúde do Trabalhador para o enfrentamento dos problemas de saúde mental associados ao trabalho, problemática que tem ganhado proporções alarmantes no Brasil e no exterior.

Reúne textos de gêneros diversos, alguns mais científicos, outros mais técnicos, de maneira explícita, conforme explicam as organizadoras:

\begin{abstract}
A proposta do livro é percorrer um caminho que vai da teoria à prática em saúde mental no trabalho, tendo como objetivos: apresentar conceitos básicos e metodologias que permitam compreender as dinâmicas de trabalho debilitantes, as vivências subjetivas e os mecanismos de enfrentamento e defesa adotados individual e coletivamente pelos trabalhadores. E mais, apresentar formas de reconhecer os agravos à saúde mental possivelmente relacionados à situação de trabalho; destacar técnicas que auxiliem no estabelecimento do nexo causal com o trabalho e avaliação de incapacidade, bem como na elaboração de laudos e relatórios; discutir casos reais ilustrativos das diversas abordagens; e analisar diferentes níveis de prevenção em saúde mental no trabalho. (p. VII)
\end{abstract}

A leitura dos diversos capítulos confirma a intenção das organizadoras: o livro explora a diversidade de abordagens, de objetos, de questões, sem ter como preocupação central a discussão das possíveis diferenças disciplinares, mas privilegiando a oferta de ampla gama de opções - uma caixa de ferramentas - deixada para os leitores, profissionais que podem escolher as mais adequadas às situações da prática.

Trata-se, portanto, de textos, em sua maioria, voltados à prática profissional e a algumas de suas vertentes: diagnóstico e nexo com trabalho (JARDIM; RAMOS; GLINA, cap. 3), aspectos periciais e avaliação da capacidade (CAMARGO, cap. 4), reabilitação profissional (LANCMAN; TOLDRÁ; SANTOS, cap.5), prevenção do estresse no trabalho (GLINA; ROCHA, cap. 6), discussão de casos clínicos, tais como transtorno pós-traumático (SELIGMANN-SILVA, cap. 18), depressão (BORGES, cap. 19), intoxicação por produtos químicos (GLINA; CAMARGO, cap. 21).
Dois objetos da prática têm maior destaque: A questão do "assédio moral", problemática das mais atuais no campo da Saúde do Trabalhador, é contemplada em três capítulos (HELOANI; BARRETO, cap. 2; SOBOLL, cap. 17; GLINA, cap. 22). No que nos concerne, a concepção proposta por Sobol merece ser sublinhada, pois considera o fenômeno sob o prisma da organização, o que abre perspectivas mais concretas à prevenção.

O binômio estresse/síndrome de burnout, por sua vez, é tratado em quatro capítulos (GLINA, cap. 1; GLINA; ROCHA, cap. 6; TRIGO, cap. 8; JARDIM; VIEIRA, cap. 20).

Não obstante, a contribuição da pesquisa também ocupa espaço de duas maneiras principais. De um lado, diversos estudos ilustrando diferentes métodos, situações de trabalho e categorias de trabalhadores são apresentados: um estudo qualitativo em trabalhadores de indústria de lâmpadas (GLINA, cap. 9), um estudo do trabalho de professores da Paraíba e do Rio de Janeiro (NEVES; BRITO; ATHAYDE, cap. 13), o estudo da saúde de analistas de sistemas (ROCHA; FERREIRA JUNIOR, cap. 16), uma análise comparativa da trajetória de distúrbios osteomusculares no Brasil e na Alemanha (ELKELES; SELIGMANN-SILVA, cap. 15), dois estudos sobre a saúde e o trabalho bancário - o primeiro (BORGES, cap. 14) combinando métodos quantitativos e qualitativos e o segundo (SOBOLL, cap. 17), de natureza qualitativa sobre o impacto do assédio moral.

Por outro lado, a contribuição das principais disciplinas e abordagens metodológicas no estudo da relação entre trabalho e saúde mental [com exceção da "Clínica da Atividade" de Yves Clot (2006)] tem papel de destaque na obra: fatores psicossociais e o modelo demanda-controle (ARAÚJO, cap. 7), Psicodinâmica do Trabalho (UCHIDA; LANCMAN; SZNELWAR, cap. 10), Ergologia (ATHAYDE; MUNIZ; FRANÇA; FIGUEIREDO, cap. 12) e a Ergonomia da Atividade (ASSUNÇÃO; LIMA, cap. 11). Os capítulos referentes aos três primeiros têm o mérito de fazer a síntese da evolução conceitual, metodológica de cada abordagem ou disciplina. No caso do capítulo sobre Ergonomia, evoca-se não apenas o efeito provocado pelo aumento das exigências afetivas ou pela presença da emoção na realização da atividade dos trabalhadores, mas também à própria metodologia da Análise Ergonômica do Trabalho. 
Nestes textos, a confrontação dos referenciais conceituais com análises de casos sobre a relação entre trabalho e saúde no setor de serviços públicos, que se constitui também em problemática bastante atual, favorece sua compreensão ao mostrar a relação entre "poder de agir em situação" (CLOT, 2010) e o sofrimento dos trabalhadores.

A análise dos trabalhadores de um Centro de Atenção Psicossocial mostra a situação paradoxal em que se encontram: como cuidar de pacientes que sofrem, sem sofrer e sem possuir recursos para fazê-lo? Assim, segundo Uchida, Lancman e Sznelwar (cap. 10):

Trabalhar no CAPS é viver uma situação em que não há enquadramento protetor e as fronteiras entre a vida profissional e pessoal são constantemente invadidas. Lá se busca construir ações em situações de grande penúria, em que é necessário recriar constantemente as práticas de saúde. O CAPS se constitui, sobretudo, em um local de cuidados que busca auxiliar os sujeitos a reconstruir a vida. O CAPS é um lugar de vida, um lugar onde as pessoas continuam a trabalhar, apesar de todo o sofrimento engendrado pelos limites à falta de estrutura. O CAPS faz sentido porque os trabalhadores se importam. (p. 206, em itálico pelos autores)

Do mesmo modo, o trabalho em serviço de urgências hospitalar público engendra sofrimento nos trabalhadores ao não lhes assegurar condições para cuidar dos pacientes, conforme afirmam Assunção e Lima (cap. 11):

Ao contrário do senso comum, os motivos de malestar na equipe de pronto atendimento não são os pacientes em situações críticas, às vezes à beira da morte, mas as condições materiais e administrativas do entorno que não permitem o máximo de envolvimento possível e necessário para salvar uma vida. Evidentemente, lidar com a morte todo o dia é um trabalho que desperta os sentimentos mais intensos, sobretudo quando se perde um paciente, mas nada se comparar à frustração de, por limitações externas, não poder fazer o possível em cada caso. (p. 225)

É inegável, portanto, o fato de que a obra oferece tanto conhecimentos e técnicas solidificadas para aplicação prática, quanto referenciais conceituais e metodológicos para entender os problemas de saúde mental no trabalho. Além disto, perspectivas interessantes para a transformação do trabalho e para a construção da prevenção, focadas na ação sobre os fatores organizacionais que estão na origem dos agravos, são abertas.

Glina e Rocha nos levam, portanto, a explorar os caminhos tortuosos da saúde mental no trabalho e nos oferecem pistas para construirmos coletivamente mecanismos de prevenção, ou seja, sua obra é um convite para a ação!

\section{Referências}

CLOT, Y. A função psicológica do trabalho. Petrópolis: Vozes, 2006.

. Trabalho e poder de agir. Belo Horizonte:

Fabrefactum, 2010.

GLINA, D. M. R.; ROCHA, L. E. Saúde mental no trabalho. São Paulo: VK/CIPA, 2000. 